\title{
Evaluation of the Immediate Dentofacial Changes in Late Adolescent Patients Treated with the Forsus ${ }^{\mathrm{TM}} \mathrm{FRD}$
}

\author{
Esen Ali Gunay \\ Tulin Arun ${ }^{b}$ \\ Didem Nalbantgilc
}

\section{ABSTRACT}

Objectives: The purpose of this study was to evaluate the short-term dentoalveolar and soft tissue changes in late adolescent patients treated with the Forsus ${ }^{\mathrm{TM}}$ FRD.

Methods: A prospective study was carried out on 54 lateral cephalometric radiograms that were taken before placement and after removal of the appliance in the treatment group (15 subjects) and at the beginning and six months after in the control group (12 subjects). The patient selection criteria were as follows: skeletal and dental Class II malocclusion due to retrognatic mandible, normal or low-angle growth pattern, post-peak growth period, no extracted or congenitally missing permanent teeth, and minimum crowding in the lower dental arch.

Results: The statistical assesment of the data suggested the following results: No sagital and vertical skeletal changes were induced. The mandibular incisors were protruded and intruded, while the maxillary incisors were retruded and extruded. The occlusal plane was rotated in clockwise direction as a result of these dentoalveolar changes. Overbite and overjet were reduced in all patients. Soft tissue profile slightly improved.

Conclusions: The results revealed that, in late-adolescent patients Forsus ${ }^{\mathrm{TM}}$ FRD corrected Class II discrepancies through maxillary and mandibular dentoalveolar changes. (Eur J Dent 2011;5:423432)

Key words: Forsus ${ }^{T M}$ FRD; Dentoalveolar changes; Hybrid appliances; Skeletal Class II malocclusion; Late adolescent treatment.

a PhD Student, Department of Orthodontics, Faculty of Dentistry, Yeditepe University, Istanbul, Turkey.

b Professor, Department of Orthodontics, Faculty of Dentistry, Yeditepe University, Istanbul, Turkey. Assistant Professor, Department of Orthodontics, Faculty of Dentistry, Yeditepe University, Istanbul, Turkey.

Corresponding author: Didem Nalbantgil, Department of Orthodontics, Faculty of Dentistry, Yeditepe University, Bagdat Cad. No: 238, Goztepe, Istanbul 34728, Turkey.

E-mail: didem.nalbantgilayeditepe.edu.tr

\section{INTRODUCTION}

Various treatment options and appliances are used for the viable treatment of Class II malocclusions, such as removable and fixed functional appliances, extraoral appliances, extraction therapy, and orthognathic surgery. Among these treatment alternatives the success of the functional therapy is mainly related to the cooperation of the patients. ${ }^{1-3}$ Compliance free inter-arch appliances such as Herbst and Jasper 
Jumper are commonly used in the correction of Class II malocclusion due to mandibular retrusion or small mandible size. Even though many studies have proved the efficacy of the Herbst, ${ }^{4-6}$ disadvantages such as requirement of complex lab work, extensive chair time, tendency to breakage, and production of rigid forces ${ }^{7-9}$ persuaded clinicians to seek for alternatives. Jasper Jumper is another appliance, which keeps the mandible in a protruded position by applying continuous, light forces that enables patients' toleration. ${ }^{10}$ On the other hand, since it does not provide rigid forces like Herbst, the skeletal effects obtained are limited. ${ }^{11-13}$

These appliances produce sagittally and vertically intrusive forces as well as expansion in the transverse direction. They also typically demonstrate mesial movement of the mandibular molars, tipping of the mandibular incisors, and variable effects associated with mandibular growth. ${ }^{14}$ The major drawback with these appliances is the tendency to breakage that can occur both in the appliance itself and in the support system. ${ }^{15}$ In order to overcome this problem, the manufacturers introduced many different variants to clinical use. Recently, hybrid fixed appliances that include coilspring type systems are preferred among others, since they are a combination of rigid and flexible fixed appliances.

Forsus $^{\mathrm{TM}}$ Fatigue Resistant Device (FRD) (3M Unitek Corp, Monrovia, Calif) is an innovative semirigid three-piece telescoping spring for Class II correction. It consists of a universal spring module, a ' $L$ ' pin and a pushrod that is available in five different sizes. The appliance has been claimed to produce continuous orthopedic forces and is designed to overcome breakage problems that can occur with other fixed functional appliances. ${ }^{16}$ It is also suggested by El-Sheikh et $\mathrm{al}^{17}$ that depending on the clinical application, the force level can be modified by varying the pushrod size to the desired force level. This feature gives the oppurtunity to clinicians to modify the force magnitude according to their preference. Therefore apart from functional therapy, Jones et $\mathrm{al}^{18}$ suggested that the Forsus ${ }^{T M}$ FRD can be an acceptable substitute for Class II elastics for patients with an average pretreatment age of 12 and who appear to be noncompliant. Additionally, it is reported that the appliance can be assembled chair-side in a relatively short amount of time since it can be incorporated into preexisting appliances easily.

It has been shown that the fixed inter-arch appliances that are used in postpeak growth period produce favorable dentoalveolar results. ${ }^{16,18,19}$ Among these wide range of appliances that are used in clinic, differences between systems and their potential effects on various age groups must be identified in order to obtain an appropriate treatment outcome that matches patients' needs. This study investigates the outcome of the Class II treatment on late adolescent patients performed by the new Forsus ${ }^{\mathrm{TM}}$ FRD and its effects on dentoalveolar and soft tissue structures.

\section{MATERIALS AND METHODS}

The study group consisted of 27 subjects (15 treated, 12 untreated) with skeletal and dental Class II malocclusions (Figure 1). The patient inclusion criteria were as follows:

- Skeletal and dental Class II malocclusion due to retrognathic mandible,

- Normal or low-angle growth pattern,

- Postpeak growth period,

- No extracted or congenitally missing permanent teeth (except third molars),

- Minimum crowding in the lower dental arch.

The study method was approved by the Yeditepe University Ethical Committee. Cervical vertebrae maturation index (CVMI) was used for all subjects to select the patients, and CVMI 5 and CVMI 6 stages which correspond to postpeak growth period was defined by lateral cephalometric radiographs (Table 1). The mean pretreatment chronological ages were 15 years 0.5 months \pm 1 year 2 months and 14 years 1 month \pm 1 year 5 months for the treatment and control groups, respectively (Table 2).

In the treatment group, the treatment of the patients were started consecutively and 0.022-inch straightwire brackets and bands were placed with a transpalatal arch in the upper jaw to minimize the anticipated transversal side effects at the upper posterior segment. In the lower anterior segment $-1.0^{\circ}$ torqued incisor brackets were used to eveluate the sole effect of the appliance on these teeth. After leveling, $0.019 \times 0.025$-inch stainless steel continuous archwires were inserted and cinched back in the upper and lower arches. Convenient sized pushrods were selected according 
to the manufacturer's instructions and connected to the lower arch between the first premolar and the canine (Figure 2). The patients were seen every four weeks, and the appliances were activated every eight weeks through wedges placed on the pushrod. The appliance was removed when a Class I or overcorrected Class I canine and molar relationship was achieved which eventuated in a mean time of 5 months 9 days \pm 1 month 16 days (Figure 3).

To eliminate the effects of growth over the treatment period, an untreated, age-matched Class II control group with skeletal and dental characteristics as similar as possible was obtained from the Faculty of Dentistry Archieve, University of Yeditepe, in Istanbul, Turkey.

Our study was carried out on 54 lateral cephalometric radiographs. Thirty of them were taken before placement and right after removal of the Forsus $^{\mathrm{TM}}$ FRD in the treated group, and 24 at the beginning and six months later in the control group. The pretreatment and posttreatment radiographs of each patient were hand-traced on acetate paper at the same time by one examiner to minimize any possible method error, and 34 measurements were identified (Table 3). The horizontal (RL1) and vertical (RL2) reference lines used in this study were also used in previous investigations. ${ }^{20-23}$

All statistical calculations were performed with NCSS 2007 software for Windows. The nonparametric Wilcoxon signed rank test was used to evaluate the differences in each group whereas; Mann-Whitney $U$-test was used to assess the differences between the groups. A confidence level greater than $5 \%$ was considered statistically not significant.

The same examiner assessed the magnitude of the method error by retracing and measuring the 20 randomly selected cephalograms after an in-
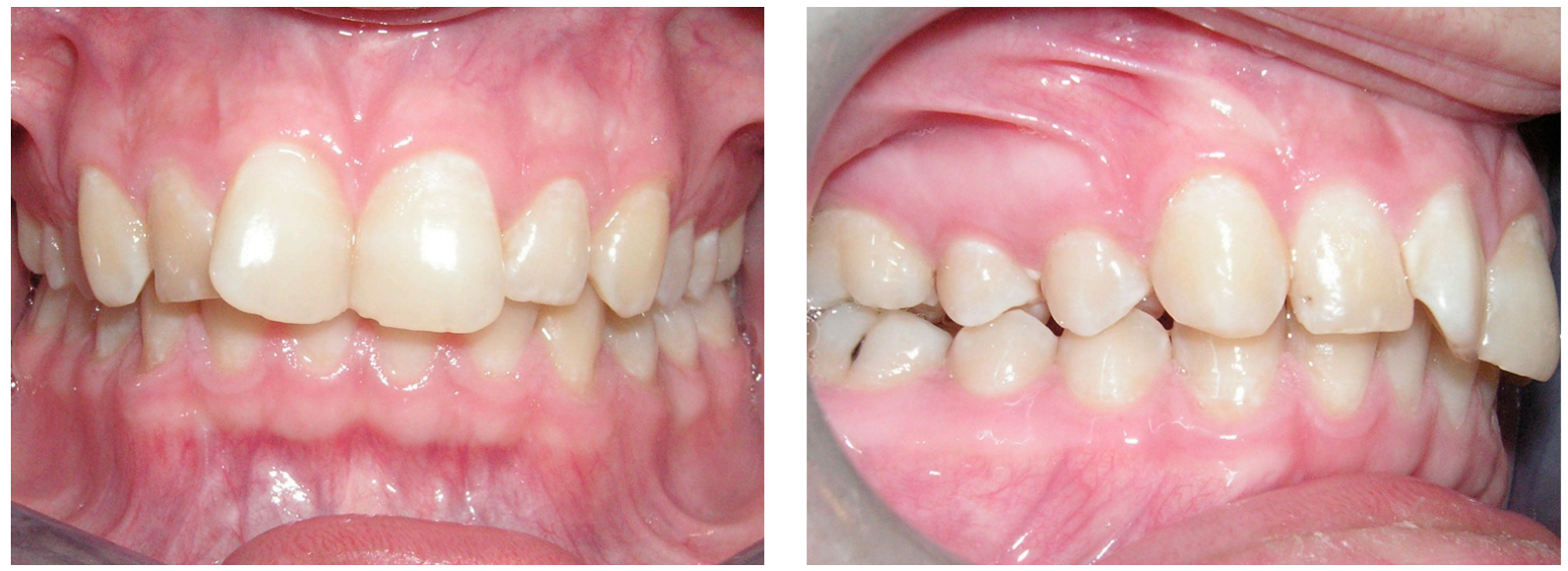

Figure 1. Intraoral photos taken at the start of the treatment.

Table 1. Cervical vertebrae maturation index distribution of treatment and control groups.

\begin{tabular}{lcccccc}
\hline & & & & CVMI 5 & & \\
& Female & Male & Female & Male & Total \\
\hline Treatment group & 4 & 2 & 5 & 4 & 15 \\
Control group & 5 & 1 & 4 & 2 & 12 \\
\hline
\end{tabular}

Table 2. Age range and sex distribution of treatment and control groups.

\begin{tabular}{|c|c|c|c|c|}
\hline Treatment group & Mean & Standard deviation & Minimum & Maximum \\
\hline Female & 14 years 9 months & 1 year 2 months & 13 years & 16 years 1 month \\
\hline Male & 15 years 4 months & 1 year 4 months & 14 years 1 month & 17 years 5 months \\
\hline Total & 15 years 0.5 month & 1 year 2 months & 13 years & 17 years 5 months \\
\hline \multicolumn{5}{|l|}{ Control group } \\
\hline Female & 14 years 6 months & 1 year 6 months & 12 years 10 months & 16 years 10 months \\
\hline Male & 14 years 2 months & 9 months & 13 years 8 months & 15 years 1 month \\
\hline Total & 14 years 1 month & 1 year 5 months & 12 years 10 months & 16 years 10 months \\
\hline
\end{tabular}


terval of 20 days. Correlation analyses were used to evaluate the findings. No statistically significant method error was observed.

\section{RESULTS}

Skeletal changes

Statistical comparisons of pretreatment and posttreatment values of the groups are shown in Tables 4-6. Comparisons of the cephalometric measurements revealed that the appliance had no skeletal effect. In the control group, SNA shows no significant change (Table 4) whereas; a statistically significant but clinically negligible increase was present in the treatment group (Table 5). When the two groups were compared, no significant change in SNA was found as seen in Table 6.

Likewise maxilla, no significant sagittal and vertical changes were found in the mandible (Table 6). In the control group although limited differences due to growth were observed at SN/MP angle and $\mathrm{Ar}-\mathrm{Pg}$ length, these were found statistically not significant when two groups were compared and no self-correction of Class II was obtained due to these changes.

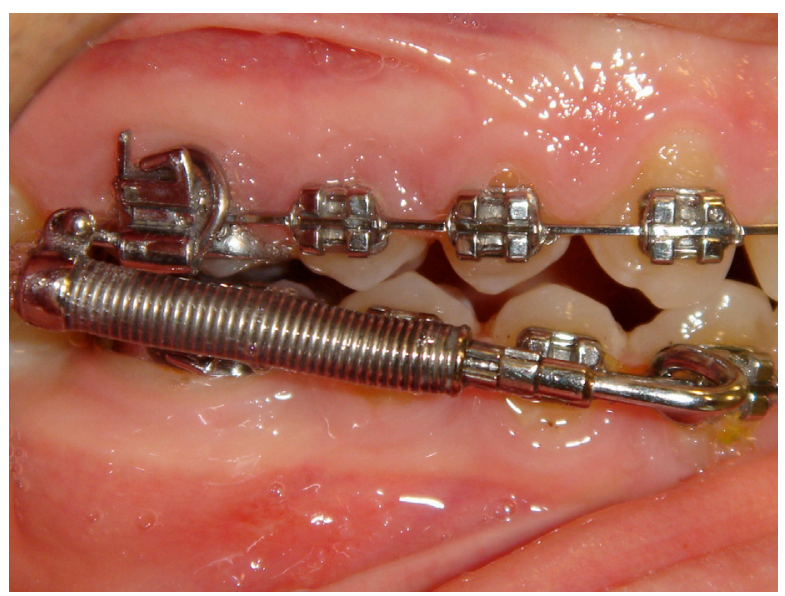

Figure 2. The application of Forsus ${ }^{\mathrm{TM}}$ FRD in the mouth
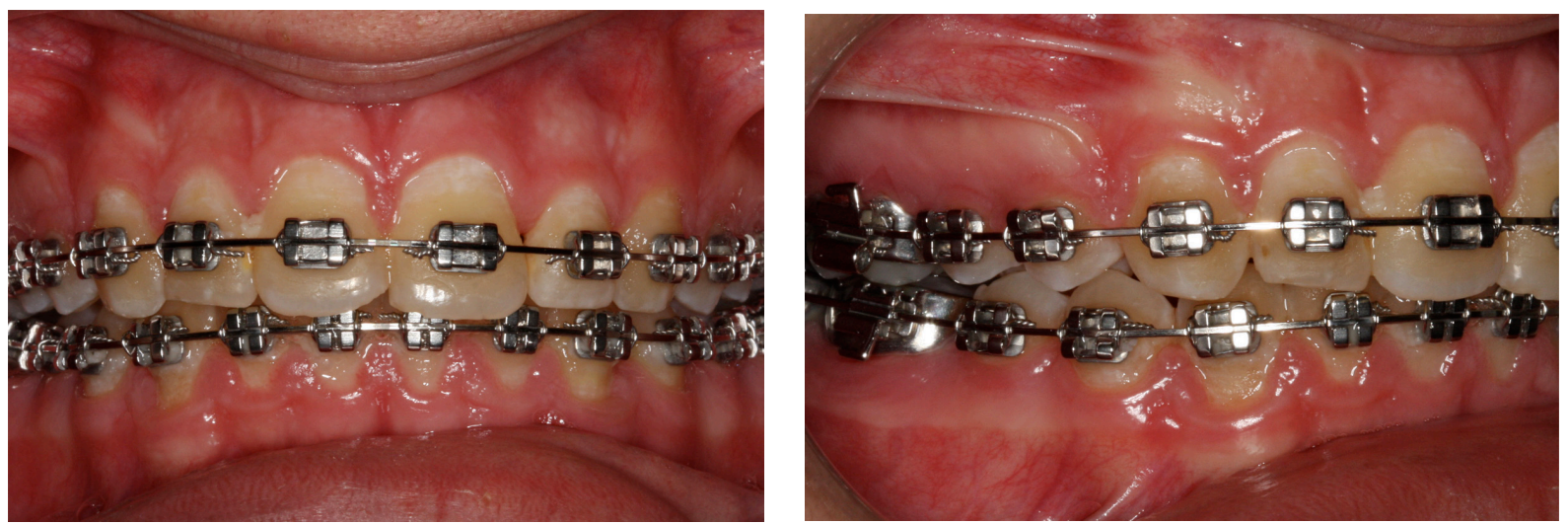

\section{Dental changes}

The dental changes caused by Forsus ${ }^{\mathrm{TM}}$ FRD in the treatment group were apparent. The upper incisors were significantly retroclined as compared with the control group (Table 6). The backward tipping of these teeth also caused them to extrude, but this vertical change was found statistically insignificant.

Conversely, in the treatment group the lower incisors showed significant proclination (Table 5). The change in IMPA displays the forward tipping of these teeth as $10.73^{\circ}$. The differences occurred relative to reference lines and at L1-NB distance also support these findings.

In the treatment group the slight insignificant decrease at the distance between the upper molar and reference line 1 (U6-RL1) revealed a minor intrusion of these teeth.

The combination of dentoalveolar changes observed both in the upper and lower jaws produced a $5.33^{\circ}$ clockwise rotation of the occlusal plane (Table 6). In addition to this, the decrease in overbite and overjet supports the incisor inclination variations caused by the appliance (Table 6).

\section{Soft-tissue changes}

The soft-tissue profile changes were found to be slightly significant. When two groups were compared, a significant decrease was seen only in the lip strength (Table 6).

In the treatment group the significant decrease observed at E line-labialis superior, Holdaway angle and lip strength reflects the changes that took place in the dentoalveolar structures (Table 5).

Figure 3. Intraoral photos taken right after the removal of Forsus ${ }^{\mathrm{TM}}$ FRD. 


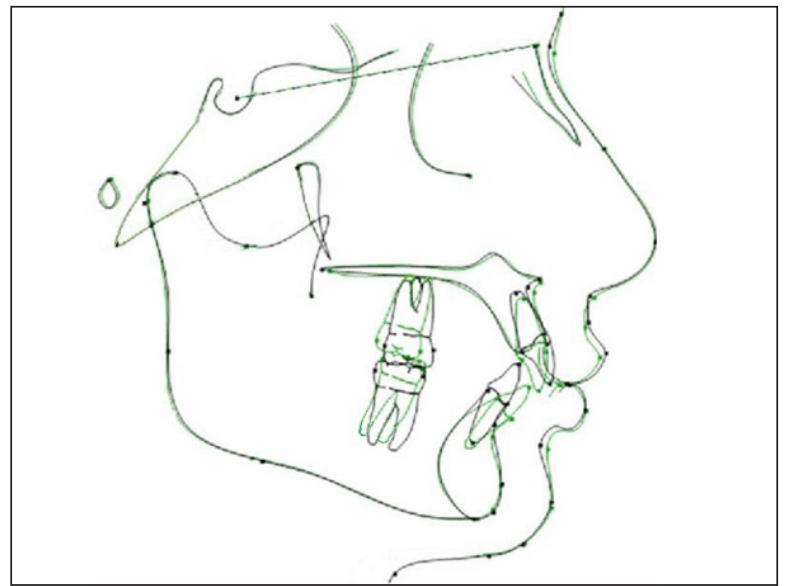

Figure 4. The total superimposition of lateral cephalometric radiograms on SellaNasion at Sella: black lines, before Forsus ${ }^{\mathrm{TM}}$ FRD application and green lines, after removal.

\section{DISCUSSION}

This study evaluated the skeletal, dental, and soft-tissue changes in late-adolescent patients treated with Forsus ${ }^{\mathrm{TM}}$ FRD. The study sample consisted of 15 patients who were at the end of their postpubertal growth period. This group who had normal or low-angle growth pattern was chosen since they could both benefit from the minimal residual growth and would have minimal relapse due to growth and posttreatment dentoskeletal changes.

The results revealed that Class II correction was achieved through dentoalveolar changes and that Forsus ${ }^{\mathrm{TM}}$ FRD had no skeletal effect on the

Table 3. Summary of cephalometric landmarks and definitions.

\begin{tabular}{|c|c|c|}
\hline & Abbreviation & Definition \\
\hline 1 & SNA (0) & The angle between the lines Sella-Nasion and Nasion-A point \\
\hline 2 & SNB $\left({ }^{\circ}\right)$ & The angle between the lines Sella-Nasion and Nasion-B point \\
\hline 3 & ANB $\left({ }^{\circ}\right)$ & The angle between the lines A point-Nasion and Nasion-B point \\
\hline 4 & SN/PP $\left({ }^{\circ}\right)$ & The angle between the lines Sella-Nasion and Palatal Plane (ANS-PNS) \\
\hline 5 & SN/MP $\left({ }^{\circ}\right)$ & The angle between the lines Sella-Nasion and Mandibular Plane (Me-Go) \\
\hline 6 & $\mathrm{SE}(\mathrm{mm})$ & The distance between Sella and E point \\
\hline 7 & $\mathrm{SL}(\mathrm{mm})$ & The distance between Sella and $L$ point \\
\hline 8 & $\mathrm{Pg}-\mathrm{NB}(\mathrm{mm})$ & The distance between Pogonion and Nasion-B point \\
\hline 9 & Ar-Pg $(\mathrm{mm})$ & The distance between Articulare and Pogonion \\
\hline 10 & A-RL2 (mm) & The distance between A point and Reference Line 2 \\
\hline 11 & B-RL2 (mm) & The distance between B point and Reference Line 2 \\
\hline 12 & A-RL1 (mm) & The distance between A point and Reference Line 1 \\
\hline 13 & ANS-Me/N-Me $[\%]$ & The ratio between lower facial height and total facial height \\
\hline 14 & Jarabak Ratio [\%] & The ratio between posterior facial height (S-Go) and anterior facial height ( $\mathrm{N}-\mathrm{Me}$ ) \\
\hline \multirow[t]{2}{*}{15} & Gonial Ratio (\%) & The line drawn from Nasion to Gonion divides the gonial angle(ArGo-MeGo) into to two \\
\hline & & The ratio between the upper and lower angles is the gonial ratio \\
\hline 16 & U1/SN $\left({ }^{\circ}\right)$ & The angle between the Sella-Nasion and the upper incisor axis \\
\hline 17 & IMPA $\left({ }^{\circ}\right)$ & The angle between the Mandibular Plane (Me-Go) and the lower incisor axis \\
\hline 18 & L1/RL2 (ㅇ) & The angle between the lower incisor axis and Reference Line 2 \\
\hline 19 & Interincisal Angle $\left({ }^{\circ}\right)$ & The angle between the upper incisor axis and the lower incisor axis \\
\hline 20 & SN/OP $(0)$ & The angle between the Sella-Nasion and the Occlusal Plane \\
\hline 21 & L1/NB (mm) & The distance from the lower incisor most buccal point to the Nasion-B point \\
\hline 22 & Overjet (mm) & The distance from the lower incisor to upper incisor tips on the sagital plane \\
\hline 23 & Overbite (mm) & The distance from the lower incisor to upper incisor tips on the vertical plane \\
\hline 24 & U6-RL1 (mm) & The distance from the mesio-buccal cusp tip of upper first molar to Reference Line 1 \\
\hline 25 & U1-RL1 (mm) & The distance from the upper incisor tip to Reference Line 1 \\
\hline 26 & H Angle $\left({ }^{\circ}\right)$ & The angle between Nasion-B point and soft tissue pogonion - upper lip \\
\hline 27 & Nasolabial Angle (ㅇ) & The angle between nose tip - subnasale and subnasale - upper lip \\
\hline 28 & $\mathrm{~N}-\mathrm{A}-\mathrm{Pg}\left({ }^{\circ}\right)$ & The angle between Nasion - A point and A point - pogonion \\
\hline 29 & A-labialis superior (mm) & The distance between A point and upper lip \\
\hline 30 & E line-labialis superior $(\mathrm{mm})$ & The distance between upper lip and E Line (Soft tissue pogonion - nose tip) \\
\hline 31 & E line-labialis inferior (mm) & The distance between lower lip and E Line (Soft tissue pogonion - nose tip) \\
\hline 32 & Labialis superior-RL2 (mm) & The distance between upper lip and Reference Line 2 \\
\hline 33 & Labialis inferior-RL2 (mm) & The distance between lower lip and Reference Line 2 \\
\hline 34 & Lip strength (mm) & $\begin{array}{l}\text { The difference between the distance from the most buccal point of upper incisor to upper lip and the } \\
\text { distance from A point to soft tissue sulcus superior }\end{array}$ \\
\hline
\end{tabular}


maxilla (Figure 4). This finding is in accordance with the results of Weiland and Bantleon, ${ }^{24}$ Aelbers and Dermaut ${ }^{25}$ and Karacay et al. ${ }^{26}$ On the other hand, many other investigators who applied fixed inter-arch appliances on growing patients stated that these appliances had a high-pull headgear effect on the maxilla. ${ }^{8,11-13,27}$ This difference between our results may have arised from age variation among groups. However, unlike us Nalbantgil et $\mathrm{al}^{19}$ observed a maxillary growth restraint effect of Jasper Jumper appliance on post-peak patients.
This contradiction may be related to varience of the sample groups and different treatment mechanics.

The present study showed that in the treatment group the slight increase in SNA due to forward movement of point $A$ was a result of the backward tipping of the upper incisors. The findings of Weiland and Bantleon, ${ }^{24}$ Aelbers and Dermaut ${ }^{25}$ and Karacay et a ${ }^{26}$ confirm this result.

Similar to maxilla, no significant effect was found on the mandible. Our results are consistent

Table 4. Changes and comparisons of pretreatment and posttreatment values within the control group.

\begin{tabular}{|c|c|c|c|c|c|c|c|c|}
\hline & & \multicolumn{2}{|c|}{ Pretreatment } & \multicolumn{2}{|c|}{ Posttreatment } & \multicolumn{2}{|c|}{ Difference } & \multirow{2}{*}{$\begin{array}{c}\text { Wilcoxon } \\
\text { P }\end{array}$} \\
\hline & & Mean & SD & Mean & SD & Mean & SD & \\
\hline 1 & SNA $\left.1^{\circ}\right)$ & 81.63 & 2.5 & 81.58 & 2.85 & -0.04 & 1.8 & \\
\hline 2 & SNB $\left(^{\circ}\right)$ & 76.13 & 3.04 & 76.71 & 3 & 0.58 & 1.24 & \\
\hline 3 & ANB $\left(^{\circ}\right)$ & 5.5 & 1.91 & 4.88 & 2.67 & -0.63 & 1.11 & \\
\hline 4 & SN/PP $\left({ }^{\circ}\right)$ & 9.67 & 3.18 & 9.17 & 2.38 & -0.5 & 1.21 & \\
\hline 5 & SN/MP () & 31 & 3.48 & 30.04 & 3.65 & -0.96 & 1.71 & * \\
\hline 6 & $\mathrm{SE}(\mathrm{mm})$ & 20.44 & 2.61 & 20.29 & 2.73 & -0.15 & 0.95 & \\
\hline 7 & $\mathrm{SL}(\mathrm{mm})$ & 45.48 & 6.69 & 46.8 & 6.99 & 1.32 & 2.41 & \\
\hline 8 & $\mathrm{Pg}-\mathrm{NB}(\mathrm{mm})$ & 3.16 & 2.06 & 3.12 & 2.08 & -0.04 & 0.3 & \\
\hline 9 & $\mathrm{Ar}-\mathrm{Pg}(\mathrm{mm})$ & 97.46 & 5.98 & 98.27 & 5.63 & 0.81 & 1.06 & * \\
\hline 10 & A-RL2 (mm) & 64.74 & 3.71 & 65.15 & 4.25 & 0.4 & 1.45 & \\
\hline 11 & B-RL2 (mm) & 55.96 & 5.2 & 56.91 & 5.37 & 0.96 & 1.91 & \\
\hline 12 & A-RL1 (mm) & 46.98 & 3.02 & 46.43 & 2.77 & -0.55 & 1.18 & \\
\hline 13 & ANS-Me/N-Me (\%) & 53.93 & 2.21 & 54.32 & 1.63 & 0.42 & 1.13 & \\
\hline 14 & Jarabak Ratio (\%) & 65.84 & 3.37 & 66.62 & 3.37 & 0.79 & 0.99 & $*$ \\
\hline 15 & Gonial Ratio (\%) & 72.08 & 4.42 & 72.54 & 5.11 & 0.46 & 2.16 & \\
\hline 16 & U1/SN (0) & 100.21 & 8.38 & 101.21 & 7.93 & 1 & 3.26 & \\
\hline 17 & IMPA $\left.1^{\circ}\right)$ & 98.96 & 6.63 & 99.46 & 6.33 & 0.5 & 2.29 & \\
\hline 18 & L1/RL2 (ㅇ) & 32.67 & 7.56 & 32.33 & 7.43 & -0.33 & 2.49 & \\
\hline 19 & Interincisal Angle $\left(^{\circ}\right)$ & 130.42 & 9.63 & 129.67 & 9.2 & -0.75 & 2.84 & \\
\hline 20 & SN/OP $\left({ }^{\circ}\right)$ & 16.29 & 6.08 & 15.13 & 5.22 & -1.17 & 2.72 & \\
\hline 21 & L1/NB (mm) & 4.15 & 1.84 & 4.08 & 1.88 & -0.07 & 0.72 & \\
\hline 22 & Overjet (mm) & 2.87 & 1.59 & 2.94 & 1.47 & 0.07 & 0.81 & \\
\hline 23 & Overbite (mm) & 4.82 & 1.35 & 4.89 & 1.43 & 0.07 & 0.45 & \\
\hline 24 & U6-RL1 (mm) & 62.72 & 2.48 & 62.76 & 2.62 & 0.04 & 0.97 & \\
\hline 25 & U1-RL1 (mm) & 68.23 & 2.36 & 68.56 & 2.95 & 0.33 & 1.35 & \\
\hline 26 & H Angle $1^{\circ} \mathrm{O}$ & 10.75 & 4.05 & 10.17 & 3.91 & -0.58 & 2.75 & \\
\hline 27 & Nasolabial Angle $\left({ }^{\circ}\right)$ & 126 & 11.92 & 125.58 & 12.46 & -0.42 & 3.7 & \\
\hline 28 & $\mathrm{~N}-\mathrm{A}-\mathrm{Pg}\left({ }^{\circ}\right)$ & 172.29 & 6.5 & 173.33 & 7.16 & 1.04 & 2.01 & \\
\hline 29 & A-labialis superior (mm) & 20.18 & 1.95 & 20.81 & 2.06 & 0.62 & 1.2 & \\
\hline 30 & E line-labialis superior $(\mathrm{mm})$ & -4.26 & 1.14 & -4.41 & 1.19 & -0.15 & 0.95 & \\
\hline 31 & E line-labialis inferior (mm) & -3.23 & 1.29 & -3.34 & 1.5 & -0.11 & 0.54 & \\
\hline 32 & Labialis superior-RL2 (mm) & 79.15 & 5.32 & 80.18 & 5.78 & 1.03 & 1.73 & \\
\hline 33 & Labialis inferior-RL2 (mm) & 75 & 5.11 & 76.29 & 4.98 & 1.29 & 1.62 & * \\
\hline 34 & Lip strength (mm) & -2.02 & 2.8 & -1.84 & 2.98 & 0.18 & 1.6 & \\
\hline
\end{tabular}


with the findings of Cope et al, ${ }^{11}$ Covell et al, ${ }^{13} \mathrm{Na}$ lbantgil et $\mathrm{al}^{19}$ and Kucukkeles and Orgun, ${ }^{28}$ but contradict Weiland and Bantleon. ${ }^{24}$ This difference may be due to different appliance mechanics between Jasper Jumper appliance and Forsus ${ }^{\mathrm{TM}}$ FRD, and age variations in these studies.

In our study, no vertical skeletal changes were observed. This may have resulted from having late adolescent patients with normal or low-angle growth pattern.
The findings related to the dentoalveolar structures revealed significant treatment effects. The change in the U1/SN angle $\left(-3.6^{\circ}\right)$ showed that the upper incisors tipped palatally whereas; IMPA and L1/RL2 angle pointed out the significant proclination of the lower incisors. These results are in accordance with the findings of other functional therapy studies. ${ }^{11-13,19,24,28}$

The anterior tipping of the lower incisors is a well-known unfavorable effect of the functional

Table 5. Changes and comparisons of pretreatment and postreatment values within the treatment group.

\begin{tabular}{|c|c|c|c|c|c|c|c|c|}
\hline & & \multicolumn{2}{|c|}{ Pretreatment } & \multicolumn{2}{|c|}{ Posttreatment } & \multicolumn{2}{|c|}{ Difference } & \multirow{2}{*}{$\begin{array}{c}\text { Wilcoxon } \\
\text { P }\end{array}$} \\
\hline & & Mean & SD & Mean & SD & Mean & SD & \\
\hline 1 & SNA $\left(^{\circ}\right)$ & 77.83 & 3.75 & 78.3 & 3.73 & 0.47 & 0.79 & * \\
\hline 2 & SNB $\left({ }^{\circ}\right)$ & 73.17 & 3.22 & 73.63 & 2.98 & 0.47 & 0.97 & \\
\hline 3 & ANB $\left.1^{\circ}\right)$ & 4.67 & 2.28 & 4.67 & 1.7 & 0 & 1.48 & \\
\hline 4 & SN/PP $\left({ }^{\circ}\right)$ & 10.07 & 2.75 & 10.17 & 3.24 & 0.1 & 1.71 & \\
\hline 5 & SN/MP (0) & 31.87 & 3.87 & 31.9 & 4.29 & 0.03 & 1.95 & \\
\hline 6 & $\mathrm{SE}(\mathrm{mm})$ & 20.62 & 2.62 & 20.56 & 2.24 & -0.06 & 1.37 & \\
\hline 7 & $\mathrm{SL}(\mathrm{mm})$ & 40.79 & 5.98 & 41.73 & 6.24 & 0.94 & 2.38 & \\
\hline 8 & $\mathrm{Pg}-\mathrm{NB}(\mathrm{mm})$ & 3.47 & 1.53 & 3.27 & 1.7 & -0.2 & 0.55 & \\
\hline 9 & $\operatorname{Ar}-\mathrm{Pg}(\mathrm{mm})$ & 97.44 & 5.63 & 97.44 & 5.33 & 0 & 1.73 & \\
\hline 10 & A-RL2 (mm) & 62.85 & 5.91 & 63.38 & 6.29 & 0.54 & 1.04 & \\
\hline 11 & B-RL2 (mm) & 52.32 & 6.65 & 52.68 & 6.44 & 0.35 & 1.84 & \\
\hline 12 & A-RL1 (mm) & 48.12 & 2.97 & 48.37 & 2.41 & 0.25 & 1.98 & \\
\hline 13 & ANS-Me/N-Me (\%) & 54.71 & 1.91 & 54.31 & 2.17 & -0.43 & 1.2 & \\
\hline 14 & Jarabak Ratio (\%) & 65.05 & 3.22 & 65.97 & 3.54 & 0.92 & 2.49 & \\
\hline 15 & Gonial Ratio (\%) & 68.07 & 5.94 & 68.88 & 4.78 & 0.82 & 3.39 & \\
\hline 16 & U1/SN (ํ) & 103.17 & 6.83 & 99.57 & 6.49 & -3.6 & 6.17 & * \\
\hline 17 & IMPA $\left(^{\circ}\right)$ & 99.4 & 7.56 & 110.13 & 8.11 & 10.73 & 3.39 & $* * *$ \\
\hline 18 & L1/RL2 (ㅇ) & 34.3 & 6.03 & 44.53 & 5.29 & 10.23 & 4.61 & $* * *$ \\
\hline 19 & Interincisal Angle $\left({ }^{\circ}\right)$ & 125.53 & 7.08 & 118.93 & 6.48 & -6.6 & 6.45 & $* * *$ \\
\hline 20 & SN/OP $\left({ }^{\circ}\right)$ & 14.97 & 3.37 & 20.33 & 4.13 & 5.33 & 2.91 & $* * *$ \\
\hline 21 & L1/NB (mm) & 3.85 & 1.91 & 6.38 & 1.54 & 2.53 & 1.04 & $* * *$ \\
\hline 22 & Overjet (mm) & 5.56 & 1.78 & 1.23 & 1.19 & -4.32 & 1.87 & $* * *$ \\
\hline 23 & Overbite (mm) & 4.79 & 0.93 & 2.7 & 0.87 & -2.09 & 1.11 & $* * *$ \\
\hline 24 & U6-RL1 (mm) & 64.65 & 4.1 & 63.62 & 3.52 & -1.03 & 1.26 & \\
\hline 25 & U1-RL1 (mm) & 70.89 & 4.1 & 71.32 & 4.07 & 0.44 & 1.23 & \\
\hline 26 & H Angle $\left({ }^{\circ}\right)$ & 12.4 & 4.42 & 11.53 & 4.58 & -0.87 & 1.43 & * \\
\hline 27 & Nasolabial Angle $\left({ }^{\circ}\right)$ & 126.33 & 8.23 & 124.8 & 7.11 & -1.53 & 3.7 & \\
\hline 28 & $N-A-P g\left({ }^{\circ}\right)$ & 174.07 & 5.63 & 173.2 & 4.84 & -0.87 & 3.08 & \\
\hline 29 & A-labialis superior $(\mathrm{mm})$ & 22.79 & 2.18 & 22.06 & 2.52 & -0.73 & 1.91 & \\
\hline 30 & E line-labialis superior (mm) & -2.85 & 1.7 & -3.5 & 2.13 & -0.65 & 1.08 & * \\
\hline 31 & E line-labialis inferior (mm) & -1.7 & 2.58 & -1 & 2.25 & 0.7 & 1.63 & \\
\hline 32 & Labialis superior-RL2 (mm) & 79.26 & 6.56 & 79.12 & 7.13 & -0.15 & 2.15 & \\
\hline 33 & Labialis inferior-RL2 (mm) & 73.23 & 8.6 & 74.24 & 9.4 & 1.01 & 2.27 & \\
\hline 34 & Lip strength (mm) & 3.44 & 2.65 & 0.94 & 1.7 & -2.5 & 2.37 & $* * *$ \\
\hline
\end{tabular}

${ }^{*}: \mathrm{P}<.05,{ }^{* * *}: \mathrm{P}<.001$ 
therapy. Until today, the studies including different appliances revealed this inclination to various degrees. Likewise other investigators, we think that the use of high negative torqued lower incisor brackets or having lingual crown torque at the lower anterior segment are possible options to prevent the protrusion of the lower incisors.

The vertical force vector of the appliance tipped and intruded the upper molars in the treatment group. Eventhough no statistically significant difference was observed when two groups are com- pared, due to the vertical control obtained in the treatment group we think that Forsus ${ }^{T M}$ FRD can be used in high-angle cases. However, since retrusion of the upper incisors may cause an increase at the gingival display, high-angle patients without high smile line should be preferred.

Retrusion and extrusion of the upper incisors and intrusion of upper molars, and protrusion of the lower incisors induced a significant clockwise rotation of the occlusal plane. Other investigators reported similar effects on the occlusal plane in

Table 6. Comparison of skeletal, dental, and soft-tissue changes of the control and treatment groups related to treatment.

\begin{tabular}{|c|c|c|c|c|c|c|c|c|}
\hline & & \multicolumn{3}{|c|}{ Control group } & \multicolumn{3}{|c|}{ Treatment group } & \multirow{2}{*}{$\begin{array}{c}\text { Mann Whitney-U } \\
\text { P }\end{array}$} \\
\hline & & D & SD & Test & D & SD & Test & \\
\hline 1 & SNA $\left(^{\circ}\right)$ & -0.04 & 1.8 & & 0.47 & 0.79 & * & \\
\hline 2 & SNB $\left.1^{\circ}\right)$ & 0.58 & 1.24 & & 0.47 & 0.97 & & \\
\hline 3 & ANB $\left({ }^{\circ}\right)$ & -0.63 & 1.11 & & 0 & 1.48 & & \\
\hline 4 & SN/PP $\left({ }^{\circ}\right)$ & -0.5 & 1.21 & & 0.1 & 1.71 & & \\
\hline 5 & SN/MP () & -0.96 & 1.71 & * & 0.03 & 1.95 & & \\
\hline 6 & $\mathrm{SE}(\mathrm{mm})$ & -0.15 & 0.95 & & 0.95 & -0.06 & & \\
\hline 7 & $\mathrm{SL}(\mathrm{mm})$ & 1.32 & 2.41 & & 2.41 & 0.94 & & \\
\hline 8 & $\mathrm{Pg}-\mathrm{NB}(\mathrm{mm})$ & -0.04 & 0.3 & & 0.3 & -0.2 & & \\
\hline 9 & $\mathrm{Ar}-\mathrm{Pg}(\mathrm{mm})$ & 0.81 & 1.06 & * & 1.06 & 0 & & \\
\hline 10 & A-RL2 (mm) & 0.4 & 1.45 & & 1.45 & 0.54 & & \\
\hline 11 & B-RL2 (mm) & 0.96 & 1.91 & & 1.91 & 0.35 & & \\
\hline 12 & A-RL1 (mm) & -0.55 & 1.18 & & 1.18 & 0.25 & & \\
\hline 13 & ANS-Me/N-Me (\%) & 0.22 & 1.13 & & 1.13 & 0.23 & & \\
\hline 14 & Jarabak Ratio (\%) & 0.79 & 0.99 & $*$ & 0.99 & 0.92 & & \\
\hline 15 & Gonial Ratio (\%) & 0.46 & 2.16 & & 2.16 & 0.82 & & \\
\hline 16 & U1/SN (0) & 1 & 3.26 & & -3.6 & 6.17 & $*$ & $*$ \\
\hline 17 & IMPA (ㅇ) & 0.5 & 2.29 & & 10.73 & 3.39 & $* * *$ & $* * *$ \\
\hline 18 & L1/RL2 (ㅇ) & -0.33 & 2.49 & & 10.23 & 4.61 & $* * *$ & $* * *$ \\
\hline 19 & Interincisal Angle $\left({ }^{\circ}\right)$ & -0.75 & 2.84 & & -6.6 & 6.45 & $* * *$ & $* *$ \\
\hline 20 & $\mathrm{SN} / \mathrm{OP}\left({ }^{\circ}\right)$ & -1.17 & 2.72 & & 5.33 & 2.91 & $* * *$ & $* * *$ \\
\hline 21 & L1/NB (mm) & -0.07 & 0.72 & & 2.53 & 1.04 & $* * *$ & $* * *$ \\
\hline 22 & Overjet (mm) & 0.07 & 0.81 & & -4.32 & 1.87 & $* * *$ & $* * *$ \\
\hline 23 & Overbite (mm) & 0.07 & 0.45 & & -2.09 & 1.11 & $* * *$ & $* * *$ \\
\hline 24 & U6-RL1 (mm) & 0.04 & 0.97 & & -1.03 & 1.26 & & \\
\hline 25 & U1-RL1 (mm) & 0.33 & 1.35 & & 0.44 & 1.23 & & \\
\hline 26 & H Angle $\left.{ }^{\circ}{ }^{\circ}\right)$ & -0.58 & 2.75 & & -0.87 & 1.43 & * & \\
\hline 27 & Nasolabial Angle $\left({ }^{\circ}\right)$ & -0.42 & 3.7 & & -1.53 & 3.7 & & \\
\hline 28 & $\mathrm{~N}-\mathrm{A}-\mathrm{Pg}\left(^{\circ}\right)$ & 1.04 & 2.01 & & -0.87 & 3.08 & & \\
\hline 29 & A-labialis superior $(\mathrm{mm})$ & 0.62 & 1.2 & & -0.73 & 1.91 & & \\
\hline 30 & E line-labialis superior (mm) & -0.15 & 0.95 & & -0.65 & 1.08 & * & \\
\hline 31 & E line-labialis inferior $(\mathrm{mm})$ & -0.11 & 0.54 & & 0.7 & 1.63 & & \\
\hline 32 & Labialis superior-RL2 (mm) & 1.03 & 1.73 & & -0.15 & 2.15 & & \\
\hline 33 & Labialis inferior-RL2 (mm) & 1.29 & 1.62 & * & 1.01 & 2.27 & & \\
\hline 34 & Lip strength (mm) & 0.18 & 1.6 & & -2.5 & 2.37 & $* * *$ & * \\
\hline
\end{tabular}

*: P<.05, **: P<.01, ***: P<.001. 
their studies. ${ }^{11,13,19,24,28}$ Also, the changes in overbite and overjet are consistent with our previous dentoalveolar findings. The correction of the overjet was achieved both by the retrusion of the upper incisors and protrusion of the lower incisors. These tipping movements also led to a development of the bite. Previous functional therapy studies also pointed out to significant decreases in overbite and overjet. ${ }^{8,11-13,19,24-28}$

The soft-tissue parameters show that the Forsus $^{\text {TM }}$ FRD slightly improved the profile. The upper lip followed the backward movement of the upper incisors and this caused the lip strength decrease significantly. The lower lip was no longer captured behind the upper incisors as a result of both retrusion of the upper incisors and the support of the proclined lower incisors. Consequently, the soft tissue reflected the majority of the dentoalveolar changes. Similar soft-tissue changes were attained from previous studies. ${ }^{19,28,29}$

The spring inter-arch appliance that is used in this study did not force the mandible to posture and function in a forward position. The correction of Class II was achieved through significant dentoalveolar changes that are obtained. These results necessitate further clinical studies that will reveal the long-term TMJ effects and stability of the appliance used in late adolescence.

\section{CONCLUSIONS}

- The Forsus ${ }^{T M}$ FRD is effective for treating Class II patients.

- The Forsus ${ }^{T M}$ FRD corrected the Class II discrepancies through dentoalveolar changes. Therefore, this appliance can be an alternative to Class II elastics.

- The maxillary incisor crowns retroclined and the mandibular incisor crowns tipped forward.

- The occlusal plane rotated in a clockwise manner.

- Skeletally no vertical or saggital changes were noted. Therefore, the appliance can also be used in high-angle cases without high smile line.

\section{REFERENCES}

1. Bishara SE, Ziaja RR. Functional appliances: A review. Am $J$ Orthod Dentofac Orthop 1989;95:250-258.

2. Pangrazio-Kulbersh V, Berger JL. Treatment of identical twins with Frankel and Herbst appliances: A comparison of results. Am J Orthod Dentofac Orthop 1993;103:131-137.
3. Bondevik 0. How effective is the combined activator-headgear treatment? Eur J Orthod 1991;13:482-485.

4. Pancherz H, Haag U. The Herbst appliance-its biologic effects and clinical use. Am J Orthod 1985;87:1-20.

5. Pancherz H, Hansen K. Occlusal changes during and after Herbst treatment. A cephalometric investigation. Eur J Orthod 1986;8:215-228.

6. Pancherz H, Ruf S, Kohlhas P. "Effective condylar growth" and chin position changes in Herbst treatment: a cephalometric roentgenographic long-term study. Am J Orthod Dentofacial Orthop 1998;114:437-446.

7. Mc Namara JA, Howe RP, Dischinger TG. A comparison of the Herbst and Frankel appliances in the treatment of Class II malocclusion. Am J Orthod Dentofacial Orthop 1990;98:134-143.

8. Valant JR, Sinclair PM. Treatment effects of the Herbst appliance. Am J Orthod Dentofacial Orthop 1989;95:138-147.

9. Konik M, Pancherz H, Hansen K. The mechanism of Class II correction in late Herbst treatment. Am J Orthod Dentofacial Orthop 1997;112:87-91.

10. Blackwood HO. Clinical management of the Jasper Jumper. J Clin Orthod 1991;755-760.

11. Cope JB, Buschang PH, Cope DD, Parker J, Blackwood HO. Quantitative evaluation of craniofacial changes with Jasper Jumper therapy. Angle Orthod 1994;2:113-122.

12. Mills CM, McCulloch KJ. Case report: modified use of the Jasper Jumper appliance in a skeletal Class II mixed dentition case requiring palatal expansion. Angle Orthod 1997;4:277-282.

13. Covell DA, Trammell DW, Boero RP, West R. A cephalometric study of Class II division 1 malocclusion treated with the Jasper Jumper appliance. Angle Orthod 1999;69:311320.

14. Ritto AK. Fixed functional appliances: Trends for the next century. The Functional Orthodontist 1999;16:122-135.

15. Sanden E, Pancherz H, Hansen K. complications during Herbst appliance treatment. J Clin Orthod 2004;38:130-133.

16. Heinig N, Goz G. Clinical application and effects of the Forsus spring. A study of a new Herbst hybrid. J Orofac Orthop $2001 ; 62: 436-450$.

17. El-Sheikh MM, Godfrey K, Manosudprasit M, Viwattanatipa $\mathrm{N}$. Force deflection characteristics of the fatigue-resistant device spring: an in vitro study. World J Orthod 2007;8:3036.

18. Jones G, Buschang PH, Kim KB, Oliver DR. Class II nonextraction patients treated with the Forsus Fatigue Resistant Device versus intermaxillary elastics. Angle Orthod 2008;78:332-338. 
19. Nalbantgil D, Arun T, Sayınsu K, Ișık F. Skeletal, dental and soft-tissue changes induced by the Jasper Jumper appliance in late adolescence. Angle Orthod 2005;75:426-436.

20. Firouz M, Zernik J, Nanda R. Dental and orthopedic effects of high pull headgear in treatment of Class II division 1 malocclusion. Am J Orthod Dentofacial Orthop 1992;102:197205.

21. Rains MD, Nanda R. Soft tissue changes associated with maxillary incisor retraction. Am J Orthod Dentofacial Orthop 1982;81:481-488.

22. Talass MF, Talass L, Baker RC. Soft tissue profile changes resulting from retraction of maxillary incisor. Am J Orthod Dentofacial Orthop 1987;91:385-394.

23. Tomlak DJ, Piecuch JF, Weinstein S. Morphologic analysis of upper lip area following maxillary osteotomy via the tunneling approach. Am J Orthod Dentofacial Orthop 1984;85:488-493.

24. Weiland FJ, Bantleon HP. Treatment of Class II malocclusions with the Jasper Jumper appliance-a preliminary report. Am J Orthod Dentofac Orthop 1995;108:341-350.

25. Aelbers CMF, Dermaut LR. Orthopedics: Part I, fiction or reality a review of the literature. Am J Orthod Dentofac Orthop 1996;110:513-519.

26. Karacay S, Akin E, Olmez H, Gurton AU, Sagdic D. Forsus Nitinol Flat Spring and Jasper Jumper corrections of Class II division 1 malocclusions. Angle Orthod 2006;76:666-672.

27. Pancherz H. The mechanism of Class II correction in Herbst appliance treatment. Am J Orthod Dentofacial Orthop 1982;82:104-113.

28. Küçükkeles N, Orgun A. Correction of Class II malocclusions with a Jasper Jumper in growing patients. Eur J Orthod 1995; 17:445.

29. Weiland FJ, Droschl H. Treatment of a Class II division 1 malocclusion with the Jasper Jumper: a case report. Am J Orthod Dentofacial Orthop 1996;109:1-7. 